\title{
Genome project faces commercialization test
}

\section{- US investor recruiting leading researchers - Company aims to dominate gene sequencing}

\section{Washington \& London}

ARMED with tens of millions of dollars in capital, a private investor is making the first serious bid to commercialize the $\mathrm{Hu}$ man Genome Project. Frederick Bourke, a wealthy entrepreneur, is on a worldwide search for top genetic researchers to join a new company he plans to set up in Seattle, Washington. With state-of-the-art technology and the best talent money can buy, he aims to dominate the effort to sequence the estimated 3,000 million chemical bases of the human genome, as well as those of other species. The heads of the two teams now leading the effort to sequence the nematode, Caenorhabditis elegans are now in negotiations with Bourke and seriously considering leaving their academic posts to join the company, which has not yet been incorporated or named.

Robert Waterston, at the Washington University in St Louis and John Sulston of the UK Medical Research Council (MRC) Laboratory of Molecular Biology at Cambridge - the two principal collaborators in the $\$ 6$ million worm genome project say they are convinced that it is time to move to the next step in the effort, the development of advanced sequencing technology and eventual production-scale automation. As a highly repetitive task, large-scale gene sequencing is tailor-made for a company. Furthermore, moving this sort of 'production line' work out of academic laboratories frees university resources for basic research, they say.

The fact that Bourke might make a

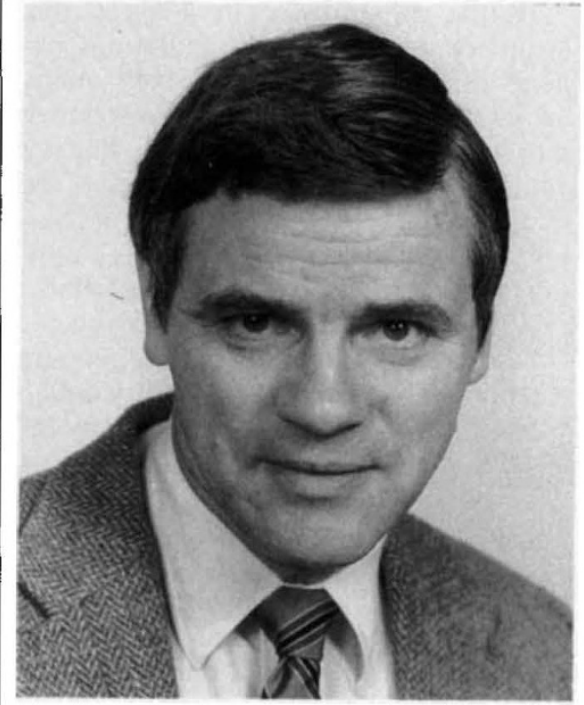

Hood's technology may launch a $\$ 50$ million company.

hefty profit by essentially monopolizing the high-efficiency gene sequencing mar- ket may bother some genome purists, but many others see it as a natural evolution of the project. "It was inevitable that the genome project would be commercialized soon," says Maynard Olson, another Washington University geneticist who is on the US Genome Project advisory panel. "It clear that the [sequencing side of the] project has to scale up in some way, and it's clear that it can't be done in an academic environment. I see no moral principal that one should turn one's back to efficient sequencing in industry."

Indeed, Olson is so taken by the concept that he has decided to leave St Louis to accept a position this summer in the new department of molecular biotechnology at the University of Washington, Seattle. Although plans have not been finalized, it appears certain that the new biotechnology department - created last year with a $\$ 12$ million gift from Microsoft co-founder William Gates - will be closely affiliated with Bourke's new company. Olson will take with him several members of his laboratory, and says that he expects to eventually have some scientific collaboration with the company.

The magnet behind this migration of leading scientists to Seattle is Leroy Hood, a gene sequencing pioneer who started Applied Biosystems Inc. (ABI), one of the largest makers of automated gene sequencing equipment. Last October, the University of Washington announced that, armed with the Gates endowment, it had recruited Hood and several members of his laboratory from the California Institute of Technology, where he is a professor and director of the university's $\mathrm{Na}$ tional Science Foundation (NSF) Science

\section{A turn of the worm}

WHAт galls researchers most about the threat of a corporate grab of the project to map and sequence the genome of the nematode $C$. elegans is not just the possibility of a derailed effort to understand a model species, but the implication for the entire Human Genome Project. C. elegans research is one of the only truly international collaborations in the 15-year, $\$ 3,000$ million undertaking, and as such, has been something of a model itself.

Robert Waterston, at Washington University in St. Louis, and John Sulston at the UK Medical Research Council (MRC) Molecular Biology laboratory in Cambridge, are by all accounts one of the success stories of the genome project. They have been collaborating on the worm for five years, and in 1990 the US National Institutes of Health (NIH) and the MRC began an unprecedented threeyear project to support jointly full-scale sequencing at the two laboratories. Total support is about $\$ 6$ million, of which
NIH provides two-thirds and MRC the rest. The money is spent equally at the two facilities.

The researchers are now about halfway through a pilot project to sequence three million of the 100 million bases in the worm genome. Given the success of the venture, and the conspicuous lack of similar collaboration elsewhere in the initiative, genome leaders would be sorry to see the worm researchers go.

"I like the idea of a big project that is shared by two countries," says James Watson, director of the NIH genome centre. "I hope that isn't lost." On the other side of the Atlantic, Dai Rees, MRC secretary, is facing the prospect of giving up a key part of one of relatively few research laboratories in which Britain is indisputably world-class. "We've put 20 years of investment into this project, and it's just reaching its culmination. It's just rather a pity if that's creamed off," he says. Rees is hoping to find enough additional money for the project to persuades Sulston to stay.
Waterston and Sulston both say that they have every intention of continuing their worm work, even if it is in a privatelyheld sequencing company in Seattle. " $C$. elegans would represent a beginning", both in learning how to sequence several hundred thousand bases a day and in interpreting those sequences, Waterston says. "That will help down the line, when you want to work on human DNA." The company will have to prove it can actually do real world sequencing, and $C$. elegans is as good a demonstration project as any, he points out.

But whether Waterston and Sulston will actually be able to finish the $C$. elegans genome in a corporate culture remains to be seen. There is, after all, little market for the nematode gene sequences themselves. Frederick Bourke, the entrepreneur who is recruiting the researchers, is hoping to turn a profit in five years. It is hard to imagine a worm standing in the way.

Christopher Anderson \& Peter Aldhous 